\title{
RECIDIVA TARDÍA DE CARCINOMA EPIDERMOIDE DE PENE
}

\author{
E. SANZ MAYAYO, R. RODRÍGUEZ-PATRÓN RODRÍGUEZ, I. GÓMEZ GARCÍA, \\ D. GARCİA ORTELLS, R. GARCÍA NAVAS, R. GARCİA GONZÁLEZ*, \\ Á. ESCUDERO BARRILERO
}

Servicio de Urología. *Servicio Anatomía Patológica. Hospital Ramón y Cajal. Madrid.

Actas Urol Esp. 27 (10): 829-831, 2003

\section{RESUMEN}

RECIDIVA TARDÍA DE CARCINOMA EPIDERMOIDE DE PENE

OBJETIVO: Presentar un caso de recidiva de carcinoma epidermoide de pene a los 21 años de la cirugía.

MÉTODO: Se trata de un paciente de 85 años con antecedentes de penectomía parcial por carcinoma epidermoide, que presenta lesión excrecente a nivel de glande de 1 mes de evolución. Se biopsia siendo el resultado carcinoma epidermoide por lo que se realiza penectomía total con uretrostomía cutánea.

RESULTADO: El estudio histopatológico de la pieza confirmó un carcinoma epidermoide bien diferenciado.

PALABRAS CLAVE: Carcinoma epidermoide de pene. Recidiva tardía.

\section{ABSTRACT \\ EPIDERMOID PENNIS CARCINOMA RECIDIVE}

OBJETIVE: We report a recidive of pennis carcinoma after 21 years of surgery.

METHODS: This is the case of a male of 85 years old, with parcial penectomy; by epidermoid carcinoma. In phisics exploration, that it displays excrecente lesion at level of glande of 1 month of evolution. Biopsy being the result of epidermoid carcinoma reason why is made.

Total penectomy, a with cutaneus uretrostomy.

RESULTS: The histopathological study of the piece, confirm a epidermoid carcinoma well differentiated.

KEY WORDS: Pennis carcinoma. Pennis carcinoma recidive.

$\mathrm{P}_{\mathrm{r}}$ resentamos el caso de un paciente con una recidiva tardía de carcinoma epidermoide de pene que genera dudas en cuanto a su origen, pudiendo ser un nuevo tumor primario o una recidiva.

Reseñamos la importancia de un seguimiento a largo plazo de este tipo de tumores tras cirugía conservadora dada la posibilidad de recidiva a largo plazo.

\section{CASO CLÍNICO}

Se trata de un paciente de 62 años con antecedentes de balanitis xerótica obliterans y papiloma venéreo sobreañadido que fue electrocoagulado en el año 1974, realizándose posteriormente circuncisión profiláctica. Presenta lesión ulcerosa a nivel de glande de 5-6 centímetros de diámetro bien delimitado y con áreas descamativas de pequeño tamaño. 
Se biopsia detectándose un carcinoma epidermoide bien diferenciado, por lo que se realiza amputación parcial de pene evolucionando satisfactoriamente (año 1981).

La histopatología confirmó un carcinoma epidermoide bien diferenciado ulcerado con infiltración superficial de glande.

El paciente se perdió para seguimiento en 1984. Es visto de nuevo en la consulta en el año 2002 presentando una tumoración en muñón distal de pene de un mes de evolución, no dolorosa de 2-3 centímetros de diámetro y de consistencia pétrea. No se apreciaban adenopatías inguinales. Se vuelve a biopsiar diagnosticándose de nuevo de carcinoma epidermoide bien diferenciado de pene. Se trata en esta ocasión mediante penectomía total dejando uretrostomía perineal.

El resultado anatomopatológico definitivo fue de carcinoma epidermoide bien diferenciado que infiltra masivamente el tejido esponjoso sin afectar a extremos quirúrgicos (Fig. 1).

\section{DISCUSIÓN}

El cáncer de pene es una patología infrecuente en países desarrollados, en Estados Unidos la incidencia es de aproximadamente de 0,2/100.000 habitantes. Presenta una incidencia superior en regiones en vías de desarrollo como África (10\% de las enfermedades malignas del varón), Asia (20\%) o áreas de Brasil. La edad media de presentación es entre los 50 y 70 años $^{1}$.

El 95\% de los tumores malignos de pene corresponde a carcinomas escamosos ${ }^{2}$.

Dentro de los factores de riesgo el más importante es la presencia de fimosis. La circuncisión se considera como un factor protector ya que evita la acumulación de esmegma, aunque todavía no se ha demostrado su capacidad oncogénica. La falta de higiene también contribuye al desarrollo de esta enfermedad. Existe asociación con el virus papiloma humano (HPV) como sucede en este caso. Muchos estudios han demostrado la presencia de HPV tipos 16 y $18^{3}$. Los cuadros de inflamación crónica (balanopostitis, liquen escleroatrófico) también pueden contribuir a su aparición ${ }^{4}$.

Existen una serie de lesiones que pueden considerarse como premalignas: leucoplasia, balanitis xerótica obliterante, enfermedad de Bowen,

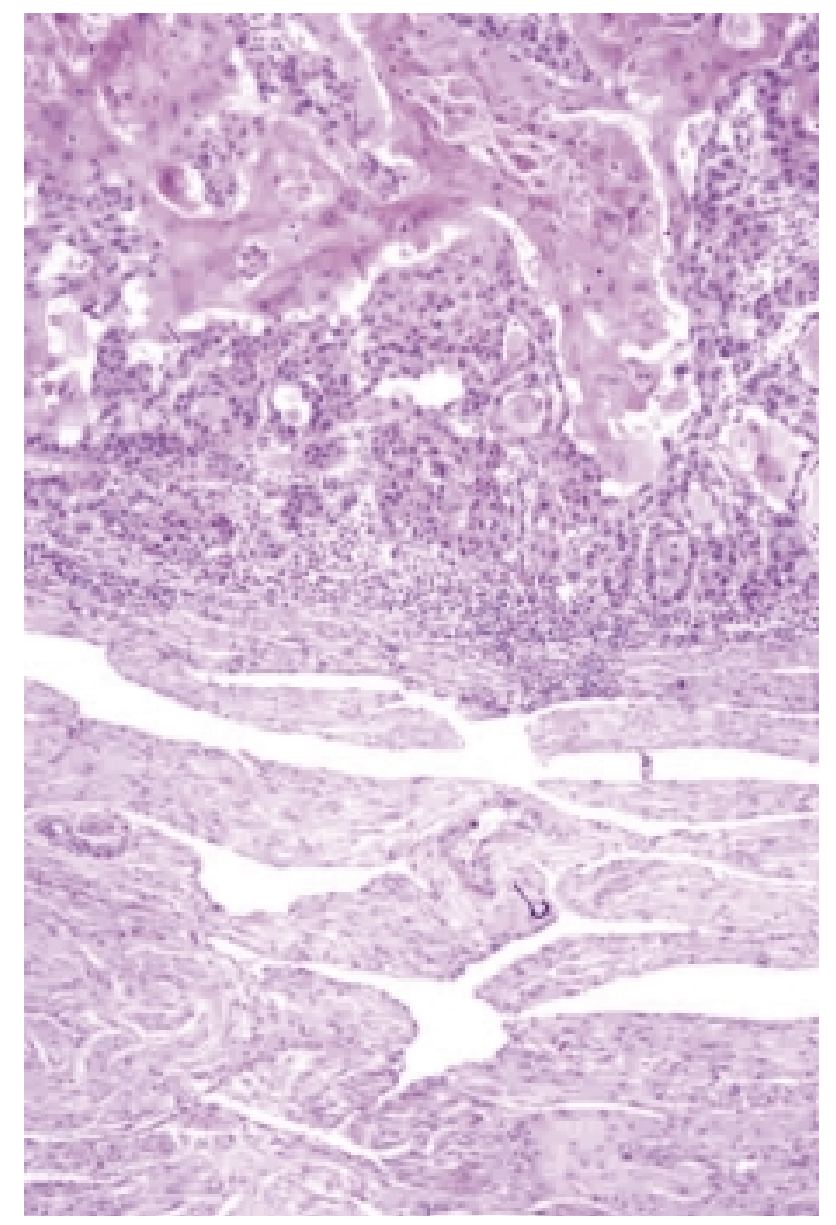

FIGURA 1. Cordones infiltrativos de una neoplasia con diferenciación escamosa, con queratinización, en relación con el cuerpo esponjoso peneano. Hex25.

eritroplasia de Queyrat, condilomas acuminados de gran tamaño, aunque la mayoría de los carcinomas escamosos aparecen sin acompañarse de ninguna lesión subyacente. En el presente caso el paciente tiene dos factores de riesgo, la balanitis xerótica y el papiloma ${ }^{1}$.

La localización más frecuente es a nivel de glande $(48 \%)$ seguida de prepucio $(20 \%)$, ambos (9\%) y surco $(6 \%)^{1}$.

Los factores pronósticos más importantes son el grado de malignidad (que varía de I a IV según la clasificación de Broder) y la profundidad de la lesión según el $\mathrm{TNM}^{5,6}$. La supervivencia global a cinco años es del $52 \%$.

El tratamiento varía dependiendo del tamaño, la localización y la profundidad de la lesión. La simple circuncisión es una posibilidad en tumores localizados a nivel de prepucio de pequeño tamaño con un margen de 2 centímetros, presen- 
tando un riesgo de recurrencia del $32 \%^{1}$. La ablación, con láser NdYAG o $\mathrm{CO} 2$ puede ser útil en tumores de pequeño tamaño y superficiales, la serie de Harenblas presenta un riesgo de recidiva del 10\% en estadío T1, 32\% en T2 y 100\% en T3 ${ }^{7}$. Otra posibilidad es la radioterapia ya sea externa o braquiterapia.

El tratamiento clásico consiste en la penectomía parcial con 1,5-2 centímetros de margen o la penectomía total con uretrostomía perineal en estadios T3 o T4. El carcinoma escamoso suele tener un crecimiento discontinuo con lesiones moteadas, por ello se suele dejar un margen de 2 cm para capturarlas ${ }^{8}$.

La terapia conservadora para tumores de pequeño tamaño T1-T2 se ha demostrado efectiva y segura, pero requiere largo periodo de seguimiento por la posibilidad de recurrencia a largo plazo. Muchas veces es difícil distinguir recurrencias locales de nuevos tumores primarios, como ocurre en el presente caso $^{9}$. La recurrencia local después de la penectomía parcial varía del 0-7\% y su manejo consiste en la penectomía total ${ }^{8}$.

\section{REFERENCIAS}

1. POW SANG MR, BENAVENTE V, POW-SANG JE et al.: Cancer of the penis. Cancer control 2002; 9: 305.

2. BURGERS JK, BADALAMENT RA, DRAGO JR et al.: Penile cancer: clinical presentation, diagnosis and staging. Urol Clin North Am 1992; 19: 247.
3. RAGHAVAN D, SCHER HI, LEIBEL SA et al.: Principles and practice of genitourinary oncology. Phyladelphia, Pa: Lippincott- Raven Publishers 1997: 921.

4. DILLNER J, VON KROGH G, HORENBLAS S et al.: Etiology of squamous cell carcinoma of the penis. Scand J Urol Nephrol Suppl 2000; 205: 189.

5. CUBILLA AL, BARRETO J, CABALLERO C y cols.: Pathologic features of epidermoid carcinoma of the penis. A prospective study of 66 cases. Am $J$ Surg Pathol 1993; 17: 75.

6. SOLSONA E, IBORRA I, RUBIO J y cols.: Prospective validation of the association of local tumor stage and grade as a predictive factor for occult lymph node micrometastasis in patients with penile carcinoma and clinically negative inguinal lymph nodes. $J$ Urol 2001; 165: 1506.

7. HORENBLAS S, VAN TINTEREN H, DELEMARRE JF et al.: Squamous cell carcinoma of the penis. II. Threatment of the primary tumor. J Urol 1992; 147: 1533.

8. LERNER SE, JONES JG, FLEISCHMANN J.: Management of recurrent penile cancer following partial or total penectomy. Urol Clin North Am 1994; 21: 729 .

9. HORENBLAS S, NEWLING DWW.: Local recurrent tumour after penis-conserving therapy. A plea for long-term follow-up. Br J Urol 1993; 72: 976.

Dr. E. Mayayo Sanz

Ctra. de Colmenar Viejo km. 9,100

28034 Madrid

(Trabajo recibido el 21 abril de 2003) 